\title{
Inhibition of endothelial cell functions and of angiogenesis by the metastasis inhibitor NAMI-A
}

\author{
A Vacca', M Bruno', A Boccarelli', M Coluccia', D Ribatti' ${ }^{2}$ A Bergamo ${ }^{3}$, S Garbisa ${ }^{4}$, L Sartor ${ }^{4}$ and G Sava*,3,5 \\ 'Department of Biomedical Sciences and Human Oncology, University of Bari, Policlinico, Piazza Giulio Cesare II, I-70124 Bari, Italy; ${ }^{2}$ Department of Human \\ Anatomy and Histology, University of Bari, Policlinico, Piazza Giulio Cesare II, I-70I 24 Bari, Italy; ${ }^{3}$ Fnd. Callerio, Via A. Fleming 22-31, 34I 27, Trieste, \\ Italy; ${ }^{4}$ Institute of Histology and Embryology, University of Padova, via G. Colombo 335122 Padova, Italy; ${ }^{5}$ Department of Biomedical Sciences, \\ University of Trieste, via L Giorfiere 7 34127, Trieste, Italy
}

NAMI-A is a ruthenium-based compound with selective anti-metastasis activity in experimental models of solid tumours. We studied whether this activity was dependent on anti-angiogenic ability of NAMI-A. We thus investigated its in vitro effects on endothelial cell functions necessary for angiogenesis to develop, as well as its in vivo effects in the chick embryo chorioallantoic membrane model. Endothelial cell proliferation, chemotaxis, and secretion of the matrix-degrading enzyme metalloproteinase2 were inhibited by NAMI-A in a dose-dependent manner, and without morphologic signs of cell apoptosis or necrosis. Lastly, NAMI-A displayed a dose-dependent in vivo anti-angiogenic activity in the chorioallantoic membrane model. These data suggest that the anti-angiogenic activity of NAMI-A can contribute to its anti-metastatic efficacy in mice bearing malignant solid tumours.

British Journal of Cancer (2002) 86, 993 -998. DOI: 10.1038/sj/bjc/6600I76 www.bjcancer.com

(c) 2002 Cancer Research UK

Keywords: angiogenesis; chemotaxis, endothelial cell; MMPs; ruthenium

Ruthenium-based compounds have recently received an increased attention as tools for investigating new anti-tumour agents (Clarke and Stubbs, 1996; Sava et al, 1999a). Some of them have reached an advanced milestone in the pre-clinical investigation (Keppler et al, 1990; Sava et al, 1998a) and one, namely imidazolium trans-imidazoledimethylsulfoxidetetrachlororuthenate (NAMI-A) (Mestroni et al, 1998), is successfully completing a phase I clinical trial at the Netherlands Cancer Institute of Amsterdam (J Schellens, personal communication). The initial evidences on the mode of action of NAMI-A, although far from the clear elucidation, showed this compound free of direct cytotoxicity for tumour cells and of effects on primary tumour growth (Sava et al, 1998a; Bergamo et al, 1999; Zorzet et al, 2000). Accumulated evidences indicated that NAMI-A inhibits metastasis growth by a selective effect on the relationship between metastatic cell and host environment, the importance of which for cell survival is well documented (Gregoire and Lieubeau, 1995; Nicolson and Menter, 1995; Radinsky, 1995). NAMI-A stimulated fibrosis growth at primary tumour site, with increased thickness of tumour capsule, cohesion among tumour cells and reduced vascular invasion of tumor mass (Sava et al, 1998a). Importantly, NAMI-A differs from most of the so-called anti-metastatic agents in that it is not only active in preventing metastasis formation but shows also good activity in inhibiting those already formed and in advanced stage of growth, this effect being very likely responsible for the increased survival time of the treated animals (Sava et al, $1999 b)$. Since the metastasis occurrence is angiogenesis-dependent (Carmeliet and Jain, 2000) we assessed the hypothesis that the

*Correspondence: G Sava; E-mail: g.sava@callerio.org Received I4 May 200I; revised 15 November 200I; accepted 10 January 2002 anti-metastasis activity of NAMI-A was correlated, at least partly, with its anti-angiogenic properties.

\section{MATERIALS AND METHODS}

\section{Compound and treatment}

Imidazolium trans-imidazoledimethylsulfoxide tetrachlororuthenate, ImH[trans- $\left.\mathrm{RuCl}_{4}(\mathrm{DMSO}) \mathrm{Im}\right]$ (NAMI-A), was prepared according to already reported procedures (Mestroni et al, 1998), and diluted stepwise from $240 \mu \mathrm{M}$ to $5 \mu \mathrm{M}$ with the culture medium of endothelial cells.

\section{Cell cultures}

The human umbilical vein endothelial cells (HUVEC) were prepared as described previously (Bussolino et al, 1992) and grown in Petri dishes coated with $1 \%$ gelatin (Sigma Chemical Co, St Louis, MO, USA) in M199 medium supplemented with 20\% foetal calf serum (FCS), $0.02 \%$ extract of bovine brain, and $0.01 \%$ porcine heparin (both from Sigma). The human endothelial-like immortalised cell line EA.hy926, derived from the fusion of HUVEC with the lung carcinoma cell line A549 (Edgell et al, 1983) was maintained in Dulbecco's modified Eagle's medium (DMEM) supplemented with 10\% heat-inactivated FCS, $1 \%$ glutamine, amphotericin $\mathrm{B}\left(2.5 \mathrm{mg} \mathrm{ml}^{-1}\right)$, penicillin $\left(100 \mathrm{U} \mathrm{ml}^{-1}\right)$, and streptomycin $\left(50 \mathrm{mg} \mathrm{ml}^{-1}\right)$. The neuroblastoma SK-N-BE and fibrosarcoma HT-1080 human cell lines were cultured in DMEM supplemented with 10\% FCS, 2 mM glutamine and penicillin/streptomycin, $100 \mathrm{U} \mathrm{ml}^{-1}$ and $50 \mathrm{mg} \mathrm{ml}^{-1}$ respectively; NIH3T3 mouse embryo fibroblasts (American Type Culture Collection, ATCC, Rockville, MD, USA) were cultured in DMEM supplemented with $10 \%$ FCS and $1 \%$ glutamine. 


\section{Preparation of conditioned media}

The conditioned media (CM) of HUVEC, EA.hy 926, SK-N-BE, HT-1080 and NIH3T3 cells were prepared by incubating subconfluent cells in a T25 flask with $6 \mathrm{ml}$ of serum-free medium (SFM) for $24 \mathrm{~h}$. The supernatant was collected under sterile conditions, centrifuged sequentially at 1200 and $12000 \mathrm{rpm}$ for $10 \mathrm{~min}$ to eliminate debris, and stored at $-20^{\circ} \mathrm{C}$.

\section{Proliferation assay}

HUVEC or EA.hy926 endothelial cells were plated in 96-well plates $\left(2.5 \times 10^{3}\right.$ cells well $\left.^{-1}\right)$ in complete medium. After $24 \mathrm{~h}$ from seeding (day 0) and on days 2 and 4, the medium was replaced (in quadruplicate) with complete medium containing NAMI-A, with complete medium alone (positive control), or with starvation SFM (negative control). Cell number was estimated on day 6 by the colorimetric method of Kueng et al (1989). Briefly, cells were fixed for $15 \mathrm{~min}$ at room temperature with $2.5 \%$ glutaraldehyde, stained for $20 \mathrm{~min}$ with $0.1 \%$ crystal violet in $20 \%$ methanol, solubilised with $10 \%$ acetate, and read at $595 \mathrm{~nm}$ (Microplate Reader 3550, Bio-Rad Laboratories, Richmond, CA, USA). Cell number was derived from a calibration curve set-up with a known number of cells. NAMI-A effects upon endothelial cell proliferation were evaluated also after treatment times shorter than $144 \mathrm{~h}(48 \mathrm{~h}$, $72 \mathrm{~h}$ and $96 \mathrm{~h}$ ), as well as in the same experimental conditions used for chemotaxis and matrix metalloproteinase assays, i.e., after 24- and 18-h treatment times.

\section{Chemotaxis assay}

This was carried out by the Boyden chambers as described previously (Vacca et al, 1999). HUVEC or EA.hy926 endothelial cells, pre-treated for $24 \mathrm{~h}$ with NAMI-A, were treated with trypsine $(0.05 \%)$ and acetate $(0.02 \%)$, collected by centrifugation, re-suspended in DMEM supplemented with $0.1 \%$ bovine serum albumin (BSA, Sigma Chemical Co), and seeded in triplicate in the upper compartment of a Boyden chamber $\left(1.2 \times 10^{5}\right.$ cells/ $400 \mu \mathrm{l})$. The lower compartment was filled with $200 \mu \mathrm{l}$ of the NIH3T3 CM as chemo-attractant or with DMEM supplemented with $0.1 \% \mathrm{BSA}$ as negative control (to evaluate random migration). The two compartments were separated by a polycarbonate filter $(12 \mu \mathrm{m}$ pore size, Nucleopore, Costar, Cambridge, MA, USA) coated with $0.005 \%$ gelatine to allow cell adhesion. After 6-h incubation in humidified $5 \% \mathrm{CO}_{2}$ air at $37^{\circ} \mathrm{C}$, cells on the upper side of the filter were removed, whereas those which had migrated to the lower side were fixed in absolute ethanol, stained with toluidine blue, and counted in 5 to 8 oil immersion fields at $400 \times$.

\section{MMP-2 sodium dodecylsulfate-polyacrylamide gel electrophoresis (SDS - PAGE) activity}

Effect on MMP-2 secretion by EA.hy926 cells T25 flasks of EA.hy 926 cells at $80 \%$ confluence were rinsed twice with serumfree DMEM and incubated for $18 \mathrm{~h}$ in this medium either alone (positive control) or in the presence of NAMI-A. Culture media were collected, and the total protein content measured by the Bradford method (Bio-Rad Laboratories), using BSA as standard. To visualise the gelatinolytic activity of MMP-2 secreted in the CM, $20 \mu \mathrm{g}$ aliquots of CM proteins were applied to 7.5\% SDS-PAGE co-polymerised with type A gelatine from porcine skin (Sigma Chemical Co) at a final concentration of $0.6 \mathrm{~g} \mathrm{l}^{-1}$. After electrophoresis in dual laboratory system (Protean II, Bio-Rad Laboratories), gels were washed in $2.5 \%$ Triton for $1 \mathrm{~h}$ to remove SDS, incubated for $18 \mathrm{~h}$ at $37^{\circ} \mathrm{C}$, and then stained with $0.1 \%$ Coomassie brilliant blue. The gelatinolytic regions were observed as white bands against a blue background. MMP activity was measured by scoring the intensity of bands by computerised image analysis (APPLE, Computer Inc, Cupertino, CA, USA).

\section{Chick embryo chorioallantoic membrane (CAM) assay and quantification of the angiogenic response}

Fertilized White Leghorn chicken eggs (20/group) were incubated under constant humidity at $37^{\circ} \mathrm{C}$. On the third day of incubation, a square window was opened in the shell after removal of $2-3 \mathrm{ml}$ of albumen so as to detach the developing CAM from the shell. The window was sealed with a glass of the same dimension, and the eggs were returned to the incubator. On day $8,1 \mathrm{~mm}^{3}$ sterilized gelatin sponges (Gelfoam, Upjohn Co, Kalamazoo, MI, USA) loaded with $3 \mu$ l of PBS (negative control), or containing $1.0 \mu \mathrm{g}$ per sponge of recombinant fibroblast growth factor-2 (FGF-2, R\&D System, Abingdon, UK) alone (positive control) or together with NAMI-A $(120 \mu \mathrm{M}$ and $240 \mu \mathrm{M}$, dissolved in $2 \mu \mathrm{l}$ PBS) were implanted on top of the CAM. CAMs were examined daily until day 12 and photographed in ovo with a Zeiss SR stereomicroscope equipped with the MC63 Camera System (Zeiss, Oberkochen, Germany). Blood vessels entering the sponge within the focal plane of the CAM were counted by two observers in a double-blind fashion at $50 \times$. At day 12, CAMs were processed for light microscopy. Briefly, the embryos and their membranes were fixed in ovo in Bouin's fluid, dehydrated in graded ethanols, embedded in paraffin, serially sectioned at $7 \mu \mathrm{m}$, according to a plane perpendicular to their free surface, stained with a $0.5 \%$ toluidine blue, and observed under a light microscope.

The angiogenic response was evaluated as microvessel density in the CAM area under the implant. The area occupied by microvessels was estimated by using a morphometric method of 'point counting' (Ribatti et al, 1995). Briefly, every third section with 30 serial slides from an individual specimen was analysed simultaneously by two investigators by a 144-intersection point-square reticulum of $0.125 \mathrm{~mm}^{2}$ inserted in the eyepiece of the double-head light microscope. Six randomly chosen microscopic fields of each section were evaluated at $250 \times$ for the total number of the intersection points that were occupied by vessels transversally cut (diameter ranging from 3 to $10 \mu \mathrm{m}$ ). Mean values \pm standard deviation (s.d.) for vessel counts were determined for each analysis. The vascular density was indicated by the final mean number of the occupied intersection points, expressed as a percentage of the total number of intersection points.

\section{RESULTS}

\section{Effect of NAMI-A on endothelial cells}

To evaluate the effects of NAMI-A upon endothelial cell proliferation, HUVEC or EA.hy926 cells were exposed on days 0,2 and 4 to complete medium (positive control), or to this medium admixed with different NAMI-A concentrations, or to the starvation SFM (negative control), and their proliferation rate was measured on day 6 by a colorimetric method. NAMI-A induced a dose-dependent inhibitory effect on endothelial cell proliferation (Figure 1). In the concentration range between 5 and $80 \mu \mathrm{M}$, endothelial cells were not able to proliferate as controls although maintaining their viability, thus indicating that NAMI-A produced a cytostatic effect. In contrast, the cell number at $120 \mu \mathrm{M}$ was significantly lower than the number of cells cultured in the SFM, thus indicating that NAMI-A induced cell death. Signs of cytotoxicity, namely vacuolisation, nuclear fragmentation and homogenisation, cellular shrinking or membrane blebbing, loss of elongated shape and cell detachment were indeed detected at $120 \mu \mathrm{M}$.

Both HUVEC and EA.hy926 cells, pre-treated for $24 \mathrm{~h}$ with different concentrations of NAMI-A and left to migrate towards the NIH3T3 CM chemo-attractant in the Boyden chambers, 
HUVEC

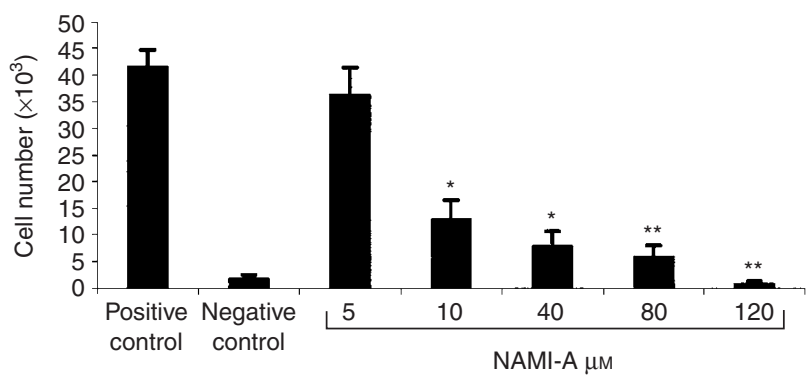

EA.hy926

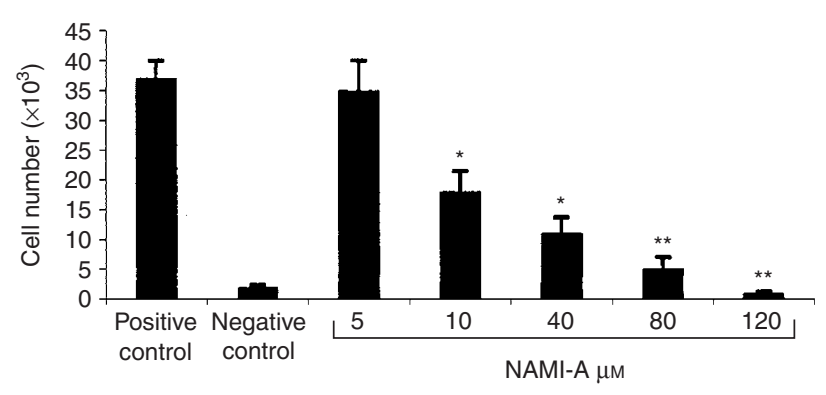

Figure I Effect of NAMI-A upon endothelial cell proliferation. Low density cultures of endothelial cells $\left(2.5 \times 10^{3}\right.$ well $\left.^{-1}\right)$ were exposed on day 0 , 2 and 4 with complete medium (positive control), serum-free medium (negative control) or complete medium containing different NAMI-A concentrations. Cell number was evaluated on day 6 by Kueng et al's method (1989). Bars, means \pm s.d. of three independent experiments. $* P<0.05$ and ** $P<0.0$ I, Student - Newman - Keuls analysis of variance.

showed a progressive dose-dependent inhibition of migration which rose $50 \%$ of the positive control at $40 \mu \mathrm{M}$ (Figure 2).

Lastly, EA.hy926 cells were exposed to increasing concentrations of NAMI-A for $18 \mathrm{~h}$, and their CM were tested for the presence and activity of MMP-2 by gelatin zymography and gelatinolysis scoring. Unexposed cells gave MMP-2 gelatinolytic band with an apparent relative molecular mass of $62 \mathrm{kDa}$ (Figure 3A), indicating that the enzyme was constitutively secreted and readily activated (Van Wart and Birkedal-Hansen, 1990). In this form, MMP-2 persisted in CM even after exposure to NAMI-A, but its secretion declined significantly at $20 \mu \mathrm{M}$ and further at $40 \mu \mathrm{M}$ (Figure 3B).

Importantly, inhibition of chemotaxis and MMP-2 production occurred without inhibition of endothelial cell proliferation. Cell number after 18- and 24-h NAMI-A treatment (40, 120 and $240 \mu \mathrm{M}$ ) was not statistically different from controls (data not shown).

\section{Effect of NAMI-A on angiogenesis in vivo}

The CAMs (20 per series) were examined macroscopically on the incubation day 12. CAMs implanted with the angiogenic factor FGF-2 (positive control) displayed a vasoproliferative response in form of allantoic vessels spreading radially towards the sponge in a spoked wheel pattern (Table 1 and Figure 4A). When the sponge was loaded with PBS, physiologic angiogenesis was observed as fewer allantoic vessels arranged partly around the sponge and partly converging towards it (Table 1). By contrast, very few vessels were detectable with $120 \mu \mathrm{M}$ and even fewer with 240 of $\mu \mathrm{M}$ NAMI-A (Table 1 and Figure 4B).

Histologic examination and planimetric vessel counting were also performed (Table 2). FGF-2-loaded sponges displayed a dense collagenous matrix and numerous blood vessels among the sponge
HUVEC

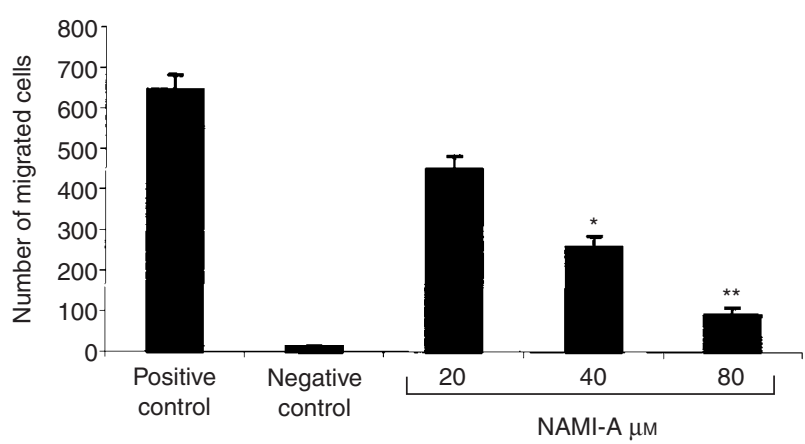

EA.hy926

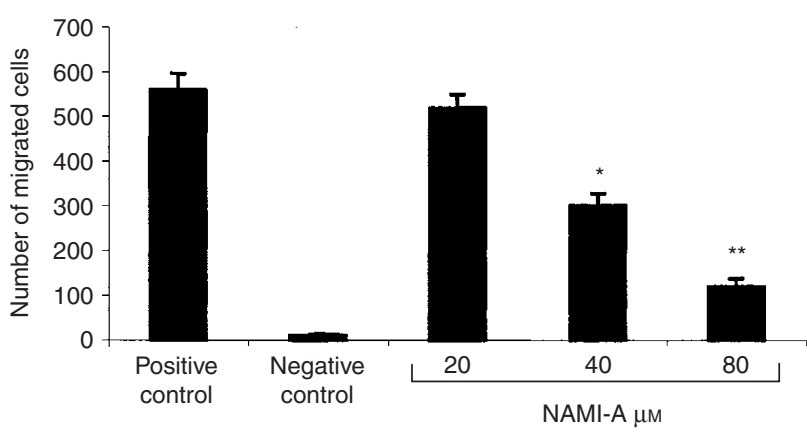

Figure 2 Effect of NAMI-A upon endothelial cell chemotaxis. $1.2 \times 10^{5}$ cells, exposed for $24 \mathrm{~h}$ to each dose of NAMI-A, were seeded in the upper compartment of the Boyden chamber, and the conditioned medium of $\mathrm{NIH} 3 \mathrm{~T} 3$ cells was placed in the lower compartment as the chemoattractant. Unexposed cells were used in the positive and negative control, respectively, the latter being devoid of the chemoattractant. Cells that migrated after $6 \mathrm{~h}$ incubation to the lower surface of the filter separating the compartments were counted. Bars, means \pm s.d. of the number of migrated cells in five to eight $400 x$ fields of three filters per specimen. $* P<0.05$ and ${ }^{*} * P<0.01$, Student - Newman - Keuls analysis of variance.

trabeculae (Table 2 and Figure 4C). By contrast, very few or no vessels could be detected inside the PBS- and NAMI-A-loaded sponges (Table 2 and Figure 4D).

\section{DISCUSSION}

NAMI-A was repeatedly described to inhibit lung metastasis growth of solid metastasising murine tumours (Sava et al, 1998a, 1999b; Zorzet et al, 2000) by a mechanism unrelated to tumour cell direct cytotoxicity (Sava et al, 1998a; Bergamo et al, 1999).

Here we show NAMI-A to inhibit a number of in vitro endothelial cell functions, namely proliferation, chemotaxis and matrix metalloproteinase production. These functions are essential steps for neovessel sprouting (Kubota et al, 1988; Connolly et al, 1989) and angiogenesis, which is an important biological process involved in metastasis formation (Liotta et al, 1991; Weidner et al, 1991). Importantly, throughout the experiment with the CAM model, this study showed NAMI-A to prevent in vivo angiogenesis at doses known to have anti-metastasis activity. In fact, NAMI-A concentration in the lung of mice bearing pulmonary metastases, following a treatment cycle (35 mg kg day ${ }^{-1}$ for six consecutive days) active on metastasis growth, is in the range 100-300 $\mu \mathrm{M}$ (Sava et al, 1998b, 1999b; Cocchietto and Sava, 2000).

In vitro inhibitory effects of NAMI-A on endothelial cell functions are dose-dependent and are obtained at non-cytotoxic 
A

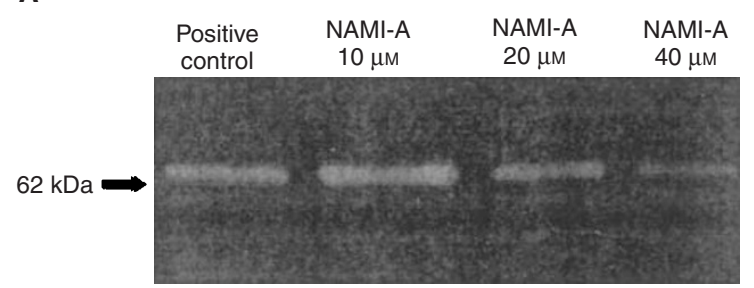

B

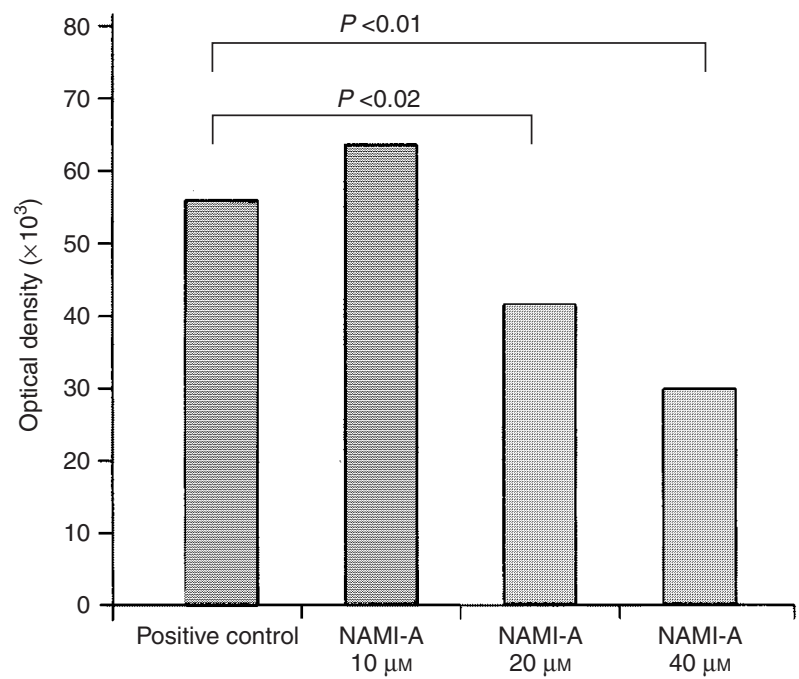

Figure 3 Effect of NAMI-A on MMP-2 production by EA.hy926 cells. MMP-2 activity was evaluated from a densitometric scan of bands resulting on a SDS/polyacrylamide/gelatin gel loaded with the conditioned medium of untreated (positive control) or NAMI-A-treated EA.hy926 cells.

Table I Chick embryo CAM-sponge assay: macroscopic assessment of vascular density on incubation day 12

\begin{tabular}{lcc}
\hline Sponge loaded with & $\begin{array}{c}\text { No. of } \\
\text { specimens }\end{array}$ & $\begin{array}{c}\text { No. of vessels at the } \\
\text { sponge-CAM boundary }\end{array}$ \\
\hline FGF-2 & 20 & $38 \pm 5$ \\
NAMI-A I20 $\mu \mathrm{M}$ & 20 & $11 \pm 6 * *$ \\
NAMI-A 240 $\mu \mathrm{M}$ & 20 & $5 \pm 3 * * * *$ \\
PBS & 20 & $9 \pm 3 * *$
\end{tabular}

Macroscopic quantitation was assessed as the number of vessels at $50 \times$ at the sponge-CAM boundary. *Results are expressed as the mean \pm I s.d. ${ }^{*} * P<0.00 \mid$ vs FGF-2 by the Student's $t$-test for unpaired data.

concentrations. In fact, the $50 \%$ inhibitory concentration of NAMI-A on both HUVEC and EA.hy926 cell proliferation is about $10 \mu$ M, i.e. a concentration more than 10 -fold lower than the cytotoxic one. Interestingly, the inhibition of endothelial cell proliferation required a rather long exposure of $144 \mathrm{~h}$. No such effect occurred with shorter challenges (up to $96 \mathrm{~h}$ ), and on other cell types such as TS/A, MCF7, B16F10 and KB NAMI-A showed a marginal cytostatic effect at $\mathrm{mM}$ concentrations whereas $10-$ $100 \mu \mathrm{M}$ NAMI-A were completely devoid of cell toxicity (Fnd Callerio, data on file). Similarly, the inhibitory effects upon chemotaxis and matrix metalloproteinase production occurred in the absence of any inhibition of cell proliferation or of cytotoxicity, thus indicating the absence of a general toxic effect on the treated cells and suggesting a peculiar mode of action of NAMI-A which deserves further investigation; studies by Pintus et al, at the Department of Biochemical Sciences of the University of Sassari, Italy, seem

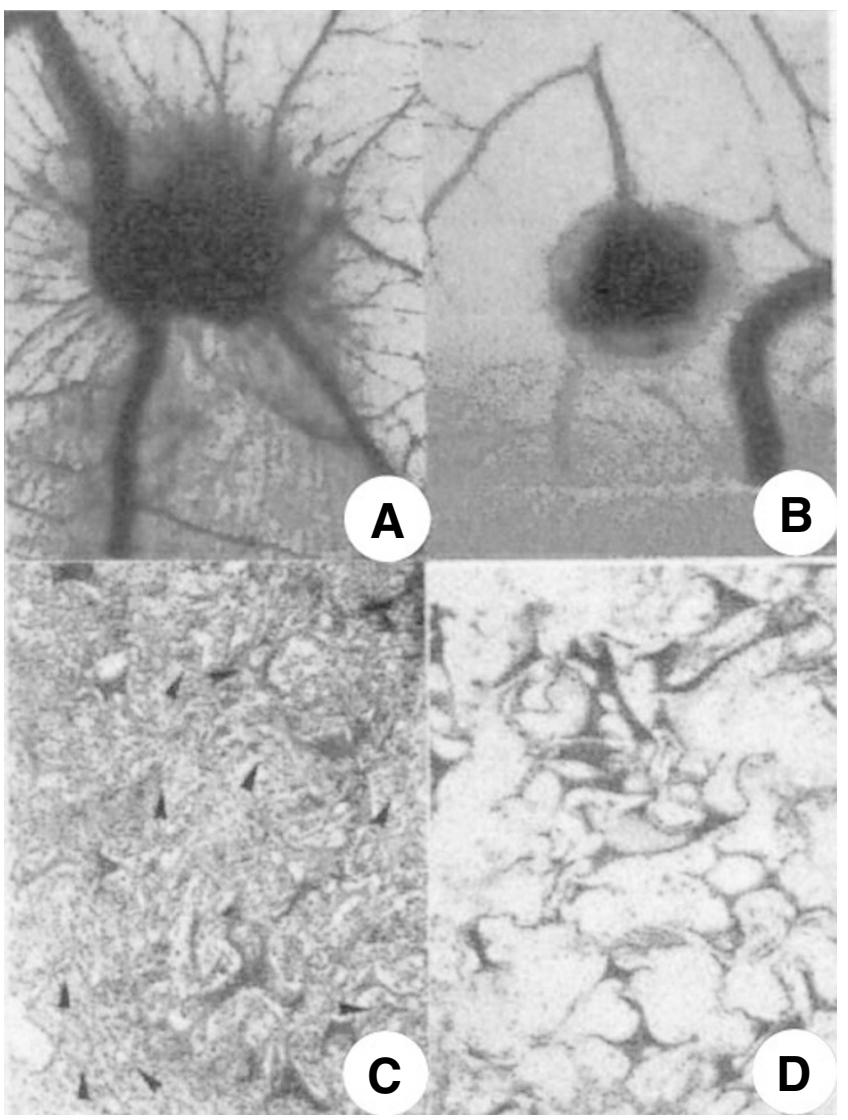

Figure 4 The CAM of a 12-day-old chick embryo incubated for 4 days with a gelatin sponge loaded with $(\mathbf{A}),(\mathbf{C})$ the angiogenic fibroblast growth factor-2 (FGF-2) or with (B), (D) $240 \mu \mathrm{M}$ of NAMI-A. Note in (A) numerous blood vessels converging like spokes toward the sponge, whereas in (B) there are very few vessels around the sponge or converging toward it. (C) Histologic section of the sponge shows numerous vessels (arrows) intermingled in a collagenous matrix among the trabeculae. (D) No vessels are detectable. Original magnifications: A, B, $50 \times$; C, D, $400 \times$

Table 2 Chick embryo CAM-sponge assay: microvessel density on day 12 of incubation

\begin{tabular}{lcc}
\hline Sponges loaded with & $\begin{array}{c}\text { No. of } \\
\text { specimens }\end{array}$ & $\begin{array}{c}\text { No. of microvessels } \\
\text { inside the sponge }\end{array}$ \\
\hline FGF-2 & 20 & $25 \pm 5$ \\
NAMI-A I $20 \mu \mathrm{M}$ & 20 & $8 \pm 4^{* *}$ \\
NAMI-A 240 $\mu \mathrm{M}$ & 20 & $3 \pm 1^{* *}$ \\
PBS & 20 & $0 * *$ \\
\hline
\end{tabular}

*Results are expressed as the mean \pm I s.d. *** $<0.01$ vs FGF-2 by the Student's t-test for unpaired data.

to confirm this hypothesis, showing NAMI-A active on the MAPK ERK1/2 pathway (G Pintus, personal communication to G Sava).

NAMI-A inhibits chemotaxis of endothelial cells and particularly the FGF-2-induced chemotaxis, since the NIH3T3 CM applied as chemoattractant contains FGF-2 as the prominent stimulatory factor (Rusnati and Presta, 1996). It also inhibits the production of MMP-2 by EA.hy926 cells. This effect appears unrelated to a general reduction of protein synthesis, since NAMI-A never did show such effect on the treated cells (Bergamo et al, 1999). However, although the evaluation of the treated cells by flow cytometry or by the sulforhodamine B test often showed an increase of cell proteins, the possibility of the selective inhibition of focal 
protein synthesis can not be excluded. MMP-2 secretion involves the degradation of type IV, V, VII and X collagens and fibronectin (Mullins and Rohrlich, 1983) which are constituents of both the basement membrane and the interstitial stroma (Tryggvason et al, 1987). This degradation facilitates the intrusion of endothelial cells across such structures, an important step for neovessel sprouting (Mullins and Rohrlich, 1983; Tryggvason et al, 1987) and metastasis formation (Tryggvason et al, 1987; Mignatti and Rifkin, 1993). Also, previous results by this group showed the inhibition of mRNAs for MMP-2, specularly to the increase of the mRNA for TIMP-2, to be associated to enhanced deposition of extracellular matrix within the tumour, increased thickness of the capsule surrounding it and appearance of a more defined wall around tumour blood vessels (Sava et al, 1996); all these events were matched to a marked reduction of the formation of spontaneous metastases.

NAMI-A can directly inhibit the enzymatic activity of MMP-2 and MMP-9, as shown by the zymography performed with conditioned medium of fibrosarcoma (HT-1080) and neuroblastoma (SK-N-BE) tumour cells (data not shown). From the experimental data, the $50 \%$ inhibitory concentration of NAMI-A can be estimated around 1-1.5 mM. This concentration is about 10-times higher than that obtained in tumour masses after a complete cycle of in vivo treatment, therefore a direct effect of NAMI-A upon matrix metalloproteinase activity appears irrelevant.

Importantly, the concentrations of NAMI-A active in vitro on endothelial cell functions, and effective in vivo in the CAM model, are easily reached from the beginning of the schedule of antimetastasis treatment. In fact, considering that (i) $24 \mathrm{~h}$ after the

\section{REFERENCES}

Bergamo A, Gagliardi R, Scarcia V, Furlani A, Alessio E, Mestroni G, Sava G (1999) In vitro cell cycle arrest in vivo action on solid metastasizing tumors, and host toxicity of the antimetastatic drug NAMI-A and cisplatin. J Pharmacol Exp Ther 289: 559-564

Bussolino F, Di Renzo MF, Ziche M, Bocchietto E, Olivero M, Naldini L, Gaudino G, Tamagnone L, Coffer A, Comoglio PM (1992) Hepatocyte growth factor is a potent angiogenic factor which stimulates endothelial cell motility and growth. J Cell Biol 119: 629-641

Carmeliet P, Jain RK (2000) Angiogenesis in cancer and other disease. Nature 407: $249-257$

Clarke MJ, Stubbs M (1996) Interactions of metallopharmaceuticals with DNA. In Metal ions in biological systems, Sigel A, Sigel H (eds) pp $727-$ 780 New York: Marcel Dekker

Cocchietto M, Sava G (2000) Blood concentration and toxicity of the antimetastasis agent NAMI-A following repeated intravenous treatment in mice. Pharmacol Toxicol 87: 193-197

Connolly DT, Heuvelman DM, Nelson R, Olander JV, Eppley BL, Delfino JJ, Siegel NR, Leimgruber RM, Feder J (1989) Tumor vascular permeability factor stimulates endothelial cell growth and angiogenesis. J Clin Invest 84: $1470-1478$

Edgell CJ, McDonald CC, Graham JB (1983) Permanent cell line expressing human factor VIII-related antigen established by hybridisation. Proc Natl Acad Sci USA 80: $3734-3737$

Gregoire M, Lieubeau B (1995) The role of fibroblasts in tumor behavior. Cancer Metastasis Rev 14: 339-350

Keppler BK, Berger MR, Heim ME (1990) New tumor-inhibiting metal complexes. Cancer Treat Rev 17: $261-277$

Kubota Y, Kleinman HK, Martin GR, Lawley TJ (1988) Role of laminin and basement membrane in the differentiation of endothelial cells into capillary-like structure. J Cell Biol 107: 1589-1597

Kueng W, Silber E, Eppenberger V (1989) Quantification of cells cultured on 96-well plates. Anal Biochem 182: 16-19

Liotta LA, Steeg PS, Stetler-Stevenson WG (1991) Cancer metastasis and angiogenesis: an imbalance of positive and negative regulation. Cell 64: $327-336$

Mestroni G, Alessio E, Sava G (1998) New salt of anionic complexes of $\mathrm{Ru}(\mathrm{III})$ as antimetastatic and antineoplastic agents. International Patent, PCT C 07F 15/00, A61K 31/28. WO 98/00431. sixth injection, NAMI-A is about $0.2 \mathrm{~mm}$ in the lungs, the site of metastasis growth, (ii) tissue distribution from the blood compartment is rather fast immediately after injection (Sava et al, 1999b; Cocchietto and Sava, 2000), and that (iii) the half-life time for elimination after repeated treatments is about $20 \mathrm{~h}$ (Cocchietto and Sava, 2000), ruthenium concentration in these tissues after the first injection is not less than one half of that found at the end of treatment.

Therefore it may be supposed that the finding that 'active' concentrations may persist in vivo in the mouse lungs for up to $48 \mathrm{~h}$ after last drug injection should warrant the exposure of the tumour cells present in these tissues for a time long enough to induce effects on the metastatic cells even greater than those presently observed in vitro.

In conclusion, this study demonstrates that NAMI-A can be credited with anti-angiogenic activity, this property probably contributing to its widely described in vivo anti-metastasis effect.

\section{ACKNOWLEDGEMENTS}

Work supported by LINFA (Laboratorio per Investigare Nuovi Farmaci Antimetastasi), Associazione Italiana per la Ricerca sul Cancro (AIRC), Milano, and Ministero dell'Istruzione, dell'Università e della Ricerca (MIUR), Rome (co-financed and 'Molecular Engineering' [Cluster 03] funds). The authors thank Dr E Alessio and Professor G Mestroni, Department of Chemical Sciences, University of Trieste, for kind preparation of the sample of NAMI-A used in the present investigation.
Mignatti P, Rifkin DB (1993) Biology and biochemistry of proteinases in tumor invasion. Physiol Rev 73: $161-195$

Mullins E, Rohrlich ST (1983) The role of proteinases in cellular invasiveness. Biochim Biophys Acta 695: 177-214

Nicolson GL, Menter DG (1995) Trophic factors and central nervous system metastasis. Cancer Metastasis Rev 14: $303-321$

Radinsky R (1995) Modulation of tumor cell gene expression and phenotype by the organ-specific metastatic environment. Cancer Metastasis Rev 14: $323-338$

Ribatti D, Urbinati C, Nico B, Rusnati M, Roncali L, Presta M (1995) Endogenous basic fibroblast growth factor is implicated in the vascularization of the chick embryo chorioallantoic membrane. Dev Biol 170: 39-49

Rusnati M, Presta M (1996) Interaction of angiogenic basic fibroblast growth factor with endothelial heparan sulfate proteoglycans. Biological implications in neovascularisation. Int J Clin Lab Res 26: 15-23

Sava G, Alessio E, Bergamo A, Mestroni G (1999a) Sulfoxide ruthenium complexes: non-toxic tools for the selective treatment of solid tumour metastases. In Topics in biological inorganic chemistry, Clarke MJ, Sadler PJ (eds) pp $143-169$ Berlin: Springer-Verlag

Sava G, Capozzi I, Bergamo A, Gagliardi R, Cocchietto M, Masiero L, Onisto M, Alessio E, Mestroni G, Garbisa S (1996) Down-regulation of tumour gelatinase/inhibitor balance and preservation of tumour endothelium by an anti-metastatic ruthenium complex. Int J Cancer 68: 60-66

Sava G, Capozzi I, Clerici K, Gagliardi R, Alessio E, Mestroni G (1998a) Pharmacological control of lung metastases of solid tumours by a novel ruthenium complex. Clin Exp Metastasis 16: 371-379

Sava G, Clerici K, Capozzi I, Cocchietto M, Gagliardi R, Alessio E, Mestroni G, Perbellini A (1999b) Reduction of lung metastasis by $\mathrm{ImH}$ trans$\mathrm{RuCl}_{4}$ (DMSO)Im]: mechanism of the selective action investigated on mouse tumours. Anti-Cancer Drugs 10: 129-138

Sava G, Gagliardi R, Cocchietto M, Clerici K, Capozzi I, Marrella M, Alessio E, Mestroni G, Milanino R (1998b) Comparison of the effects of the antimetastatic compound $\mathrm{ImH}\left[\right.$ trans- $\left.\mathrm{RuCl}_{4}(\mathrm{DMSO}) \mathrm{Im}\right]$ (NAMI-A) on the arthritic rat and on MCa mammary carcinoma in mice. Pathol Oncol Res 4: $30-36$

Tryggvason K, Hoyhtya M, Salo T (1987) Proteolytic degradation of extracellular matrix in tumor invasion. Biochem Biophys Acta 907: 191-217 
Vacca A, Iurlaro M, Ribatti D, Minischetti M, Nico B, Ria R, Pellegrino A, Dammacco F (1999) Antiangiogenesis is produced by non-toxic doses of vinblastine. Blood 94: 4143-4155

Van Wart HE, Birkedal-Hansen H (1990) The cystein switch: a principle of regulation of metalloproteases activity with potential applicability to the entire matrix metalloproteinase gene family. Proc Natl Acad Sci USA 87: $5578-5582$

Weidner N, Semple JP, Welch WR, Folkman J (1991) Tumor angiogenesis and metastasis: correlation in invasive breast carcinoma. New Engl J Med 324: $1-8$

Zorzet S, Bergamo A, Cocchietto M, Sorc A, Gava B, Alessio E, Iengo E, Sava $\mathrm{G}$ (2000) Lack of in vitro cytotoxicity, associated to increased $\mathrm{G}_{2}-\mathrm{M}$ cell fraction and inhibition of matrigel invasion, may predict in vivo-selective antimetastasis activity of ruthenium complexes. J Pharmacol Exp Ther 295: $927-933$ 